\title{
Outcome of 1890 tracheostomies for critical COVID-19 patients: a national cohort study in Spain
}

\author{
Cristina Martin-Villares ${ }^{1,5}$ (1) Carmen Perez Molina-Ramirez ${ }^{2} \cdot$ Margarita Bartolome-Benito $^{3}$. \\ Manuel Bernal-Sprekelsen ${ }^{4}$. COVID ORL ESP Collaborative Group (*)
}

Received: 14 June 2020 / Accepted: 15 July 2020 / Published online: 4 August 2020

○) Springer-Verlag GmbH Germany, part of Springer Nature 2020

\begin{abstract}
Background The question of an optimal strategy and outcomes in COVID-19 tracheostomy has not been answered yet. The critical focus in our case study is to evaluate the outcomes of tracheostomy on intubated COVID-19 patients.

Methods A multicentric prospective observational study of 1890 COVID-19 patients undergoing tracheostomy across 120 hospitals was conducted over 7 weeks in Spain (March 28 to May 15, 2020). Data were collected with an innovative approach: instant messaging via WhatsApp. Outcome measurements: complications, achieved weaning and decannulation and survival. Results We performed 1,461 surgical (81.3\%) and 429 percutaneous tracheostomies. Median timing of tracheostomy was 12 days (4-42 days) since orotracheal intubation. A close follow-up of 1616/1890 (85.5\%) patients at the cut-off time of 1-month follow-up showed that in $842(52.1 \%)$ patients, weaning was achieved, while $391(24.2 \%)$ were still under mechanical ventilation and $383(23.7 \%)$ patients had died from COVID-19. Decannulation among those in whom weaning was successful $(n=842)$ was achieved in $683(81 \%)$ patients.

Conclusion To the best of our knowledge, this is the largest cohort of COVID-19 patients undergoing tracheostomy. The critical focus is the unprecedented amount of tracheostomies: 1890 in 7 weeks. Weaning could be achieved in over half of the patients with follow-up. Almost one out of four tracheotomized patients died from COVID-19.
\end{abstract}

Keywords COVID-19 $\cdot$ Tracheostomy $\cdot$ Mechanical ventilation $\cdot$ Intensive care unit

COVID ORL ESP Collaborative group members and hospitals $(*)$ are listed in the Acknowledgements section.

\section{Cristina Martin-Villares}

crismvillares@gmail.com

1 Department of Otorhinolaryngology, Hospital Universitario El Bierzo, Médicos sin Fronteras s/n, 24401 Ponferrada, León, Spain

2 Department of Otorhinolaryngology, Complejo Universitario Hospitalario de Segovia, University of Valladolid, Segovia, Spain

3 Department of Otorhinolaryngology, Hospital Infantil Universitario Niño Jesús, Autonomous University of Madrid, Madrid, Spain

4 Department of Surgery, Otorhinolaryngology, University of Valencia, Valencia, Spain

5 Department of Medicine, Surgery and Anatomy, University of León, León, Spain

\section{Introduction}

Poor outcomes in critical patients infected with SARSCoV-2 admitted to ICUs have been reported [1-9]. In Italy, [3] 58\% of 1591 COVID-19 patients were still in ICU 5 weeks after admission and mortality rates have been over $50 \%$ in large case series [1,2]. In this pandemic scenario, with limited ICUs resources [10], tracheostomy seems to help COVID-19 patients to get off the mechanical ventilation [11], reducing the respiratory effort in patients with limited pulmonary reserves, shortening the dead space and enabling the suctioning of accumulated mucous.

Current protocols have recommended to delay tracheostomy for at least 14 days or longer or advocated to wait until a negative PCR [12-14]. However, all recommendations are neither based on the experiences of patients infected by the SARS-CoV-2 nor in a pandemic situation with overcrowded ICUs lacking proper equipment for mechanical ventilation.

The questions of an optimal strategy and outcomes in COVID-19 tracheostomies have not been answered yet. 
Spanish otolaryngologists began tracheostomies very early in the pandemic, on March 11, 2020. The rationale was to achieve fast weaning to enable incoming patients to take advantage of the released mechanical ventilation equipment. The critical focus of our case study is the unprecedented amount of tracheostomies in Spain that may serve as a lesson for this and potential future pandemics.

\section{Materials and methods}

\section{Patients}

On March 25, the Spanish COVID ORL Group was created to share experiences in the management of upper airway during this pandemic. The group has performed a national multicentric prospective observational study on 1890 COVID-19 critical patients undergoing tracheostomy in a total of 120 hospitals in Spain. The study prospectively collected data during seven consecutive weeks from March 28 to May 15, 2020 in each participating hospital.

\section{Data collection}

Clinical data were collected daily with an innovative approach: instant messaging via WhatsApp by participants. A daily report analysed data to keep all surgeons updated. Each participating hospital included: new COVID-19 patients undergoing tracheostomy, achieved weaning and decannulation of patients (as non-identified data). Also, the accumulated COVID-19-related mortality rate was registered. Data were available for all collaborators at any given time. Members of the COVID ORL group shared experiences in tracheostomy indications, performance and outcomes, but also in self-protection in COVID-19 scenario.

\section{Follow-up}

To assess the impact of tracheostomy in intubated COVID19 patients, the following outcome measurements were assessed on a daily basis: (a) indication of tracheostomy: conventional or emergency tracheostomy; (b) timing for tracheostomy (early $<10$ days or late $>10$ days); (c) technique: open or percutaneous tracheostomy; (d) perioperative complications; and (e) final outcomes: the number of patients in whom weaning and/or decannulation could be achieved, complications and survival. Follow-up of tracheotomized patients was performed until 1 month after the procedure.

\section{Results}

Over 254 otolaryngologists had registered on March 25, 2020 to participate in the COVID ORL messenger Group. This social media platform allows the large group of ENT colleagues from 120 hospitals to exchange critical information and development of a common strategy in the pandemic.

As of May 14, 2020, with 11,493 ICUs patients confirmed by the Health Ministry of Spain [15], data for 1890 COVID-19 patients who underwent tracheostomy across 120 hospitals in Spain were available. Most of tracheostomies were performed in a very short time: 1890 tracheostomies in less than 2 months (Figs. 1, 2). From March 28 to April 20 alone, during the 3 weeks of the pandemic peak in Spain, data were entered for 1400 cases. After the peak, from April 20 to May 15, further 490 cases were added. The unequal spread of COVID-19 in Spain had an impact on the number of tracheostomies in each hospital (Fig. 3).

Most tracheostomies $(n=1461 ; 81.3 \%)$ were open and the rest percutaneous $(n=429 ; 22.7 \%)$. Indication and timing of elective tracheostomy were usually established based on patient respiratory status by the ICU staff. Only

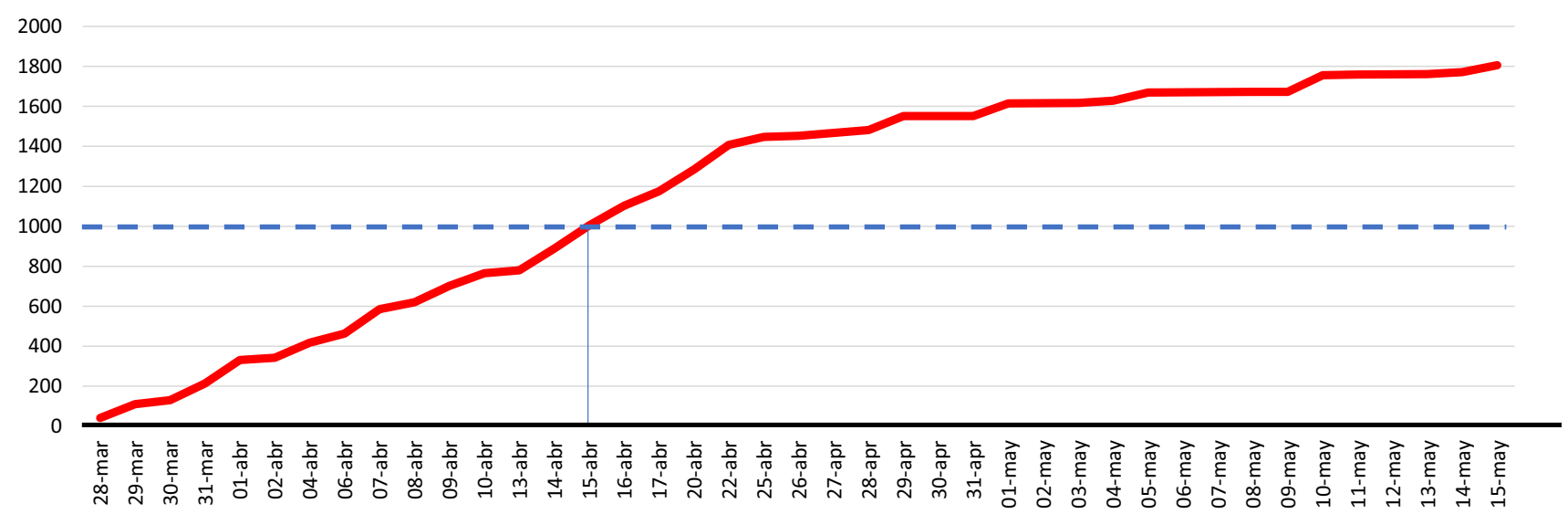

Fig. 1 Cumulative COVID-19 tracheostomies performed by COVID ORL ESP Collaborative Group 


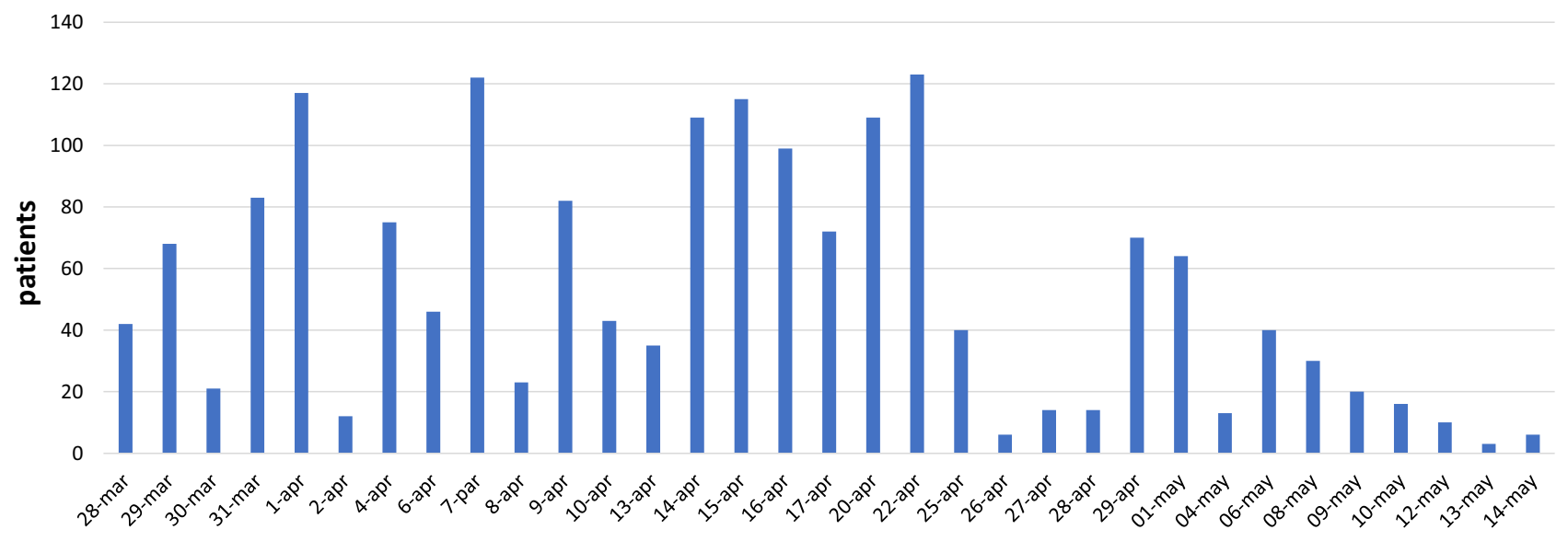

Fig. 2 Tracheostomies on COVID-19 patients per day

Fig. 3 Distribution of tracheostomies in COVID-19 patients per hospital

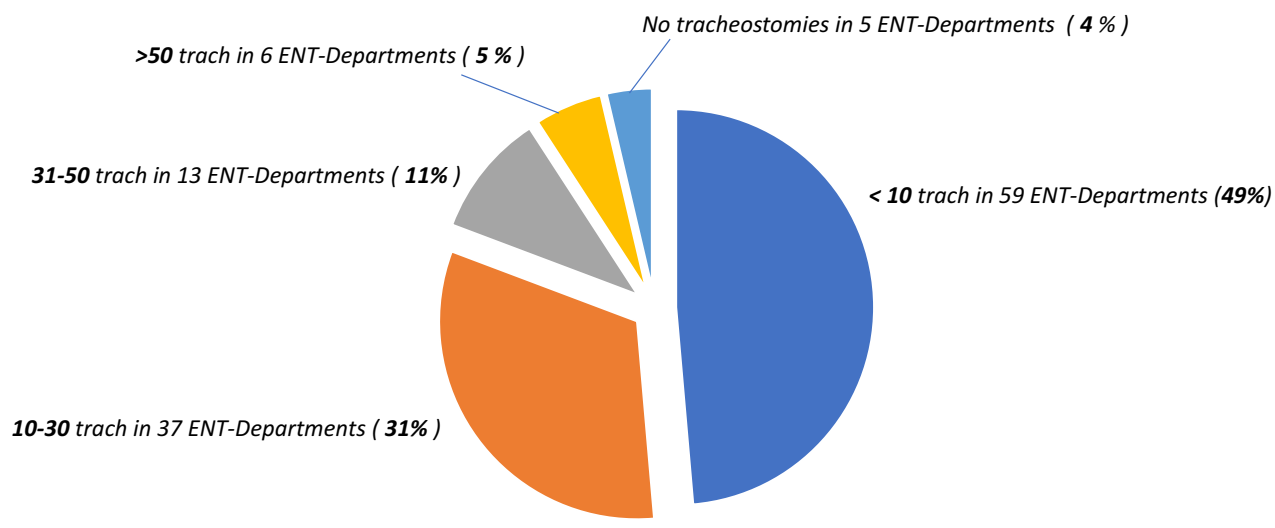

$4.6 \%$ of COVID-19 patients (88 of 1890 patients) underwent tracheostomy at a very early stage within 7 days of intubation. The median timing of tracheostomy was 12 days after intubation (range 4-42 days). Most procedures were performed at bed-side in the ICU. While almost all tracheotomies were regular procedures, four $(0.2 \%)$ were vital emergency tracheostomies.

Surgeons shared some technical modifications, such as a sub-isthmus tracheotomy approach or the use of electrocautery and harmonic scalpel, both used exclusively before opening the trachea. Most of the endotracheal tubes were found partially or subtotally blocked with sticky secretions. Only cuffed non-fenestrated tubes were used in all COVID-19 patients. Isolated cases of tracheomalacia with cuff leaking were reported.

Complication rate was low; hemorrhage was the notable major adverse outcome in 49 patients $(2.6 \%)$. One patient died from bleeding. Among other adverse events were desaturation with cardiac arrest $(n=8 ; 0.42 \%)$, right after opening the trachea, with $5(0.2 \%)$ subsequent intraoperative deaths. Pneumothorax after tracheostomy was reported in 3 cases.
All surgeons were able to use personal protective equipment (PPE) in all procedures. Standard PPE consisted of glasses, N95/FFP2 with an additional surgical mask placed above, two pairs of gloves and a face shield. Initially, PPE with powered air-purifying respirator (PARP) was available only in two hospitals. Just one vital emergency tracheotomy was performed without PPE under less optimal conditions, with only double surgical mask and glasses. The surgeons who performed this procedure were asymptomatic at 2 weeks after procedure and tested antibodies proved negative.

An overview of all outcomes is listed in Fig. 4. A close follow-up of $1616 / 1890(85.5 \%)$ patients at the time of reporting showed that in $842(52.1 \%)$ patients, weaning was achieved, while 391 (24.2\%) were still under mechanical ventilation, while 383 (23.7\%) patients died from COVID-19. Among those in whom weaning was successful $(n=842)$, decannulation could be achieved in $683 / 842$ $(81 \%)$ at the cut-off time. 


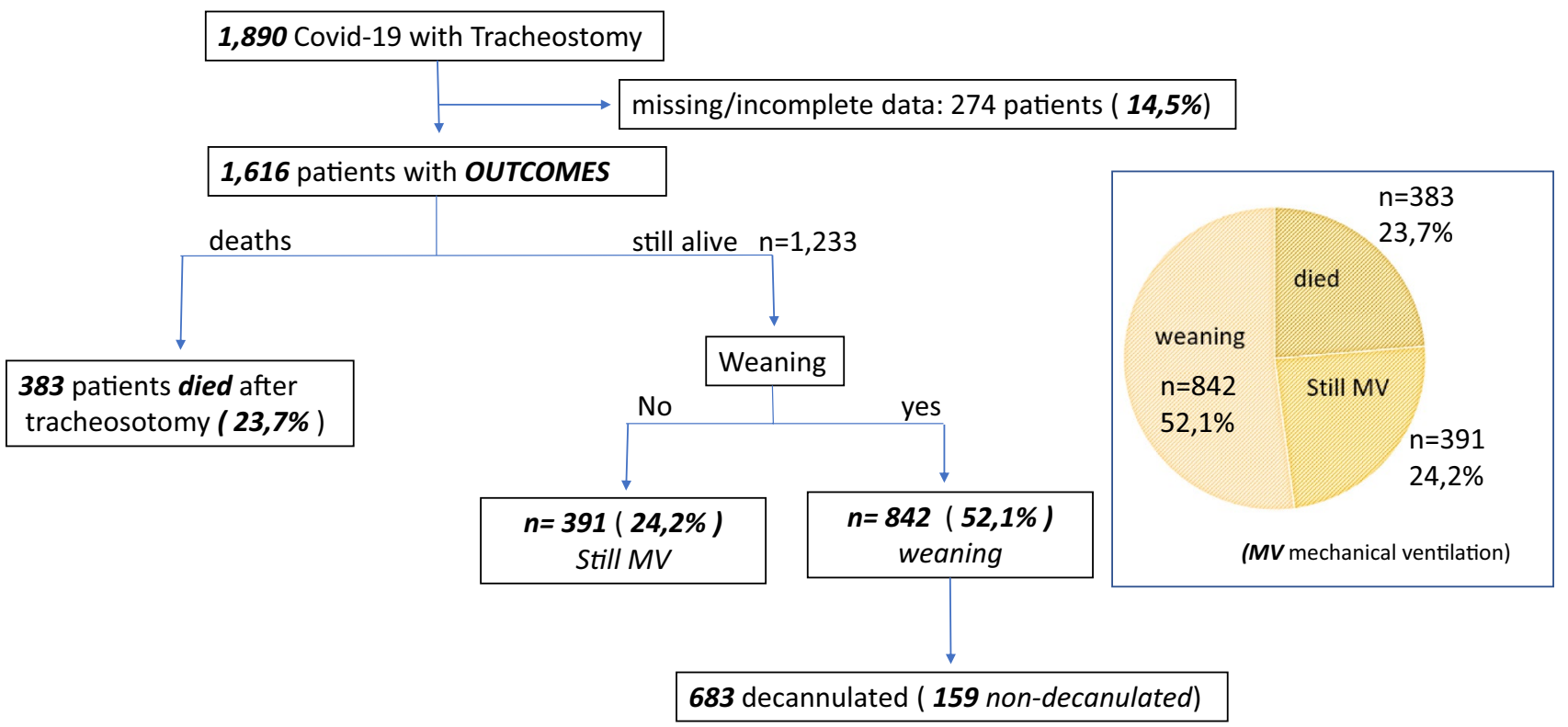

Fig. 4 Outcome of 1890 tracheostomies for critical COVID-19 patients in Spain

\section{Discussion}

On early March, 2020, at a very critical moment of the pandemic in Spain and without published data yet from initial experiences in China or Italy, Spanish otolaryngologists began their first tracheostomies in Madrid (March, 11) and Barcelona (March, 16), with the onrush of more than a thousand patients in their respective overcrowded ICUs, which doubled its current capacity. A large group of otolaryngologists started an innovative exchange of critical information focused on tracheostomy on COVID19 patients under mechanical ventilation in an attempt to coordinate among themselves and to develop a common strategy.
On May 15, the Spanish Health Ministry confirmed 11,493 ICU accumulative admissions [15]. Between March 28 and May 15, the Spanish COVID Group, encompassing 120 hospitals, performed 1890 tracheostomies, the equivalent of $16.4 \%$ of all registered ICU patients with mechanical ventilation in Spain. Herein, ENT Departments not participating in our social media group have not been considered; therefore, the number of total tracheostomies in Spain can be presumed to be even higher. To the best of our knowledge, there are no published data about such a high number of tracheostomies in COVID-19 critical care units.

The rate of tracheostomies $(16.4 \%)$ is similar to that reported in large cohort studies on Acute Respiratory Distress Syndrome (ARDS) in the LUNG-SAFE trial [16]; 13\% of ARDS patients underwent tracheostomy in ICUs of 50

Table 1 Tracheostomy in COVID-19 patients (Refs. [11, 17-24])

\begin{tabular}{lcll}
\hline Surgeon and Hospital & Patients & Timing (days) & Mortality \\
\hline Stubington TJ Derby Hospital Nottingham GB [17] & 12 & $>14$ & $16 \%(n=2)$ at 4 weeks \\
Juan Riestra-Ayora Hospital Getafe, Spain [18] & 27 & $12-13$ & $41 \%(n=11)$ at 7-days after Trach \\
Ottavi Piccin University of Bologna, Italy [19] & 24 & 10 & No data (14 decannulated) \\
Tackhar Guy's and Saint Thomas HNS, Great Britain [20] & 51 & 17 & $3.9 \%(n=2)$ at 14-days after trach \\
Luca D'Asciano Santa Croce Pesaro, Italy [21] & 22 & 21 & No data \\
Francesco Mattioli University Hospital of Modena, Italy [22] & 28 & $7-14$ & No data \\
ZF Deng Renmin Hospital of Wuhan University [23] & 4 & No data & No data \\
Mariko Hiramatsu U Nagoya Japan [24] & 1 & 11 & Survive at day 35 \\
COVID Trach Collaborative Group, UK NHS [11] & 564 & $82 \%>10$ & $12 \%(n=64)$ \\
COVID ENT ORL Group SPAIN & 1890 & 12 & $24 \%(n=383)$
\end{tabular}


countries in five continents, reaching $15.7 \%$ in European countries alone. The most recent literature in COVID-19 patients (Table 1) shows only small series that add up to 150 tracheostomies and a more large case report about 564 from 78 UK NHS hospitals, the COVID TRACH Collaborative Group [11].

Timing of the tracheostomy remains controversial [25]. Our data about the median timing for tracheostomy are 12 days (range 4-42 days) after tracheostomy. Only 4.6\% of our COVID-19 patients (88/1890) underwent tracheostomy at a very early stage within 7 days of intubation. In the COVID Trach Collaborative Group [11], only 18\% of patients underwent tracheostomy before 10 days of intubation. In the recent literature (Table 1), tracheostomy related to COVID-19 was indicated after 10-21 days of mechanical ventilation. A systematic review of 222,641 patients from 43 studies published by Adly [26] could show that early tracheostomy within 7 days reduces the complications and mortality. However, most of the patients had healthy lungs, whereas critical COVID-19 patients presented severe Acute Respiratory Distress Syndrome (ARDS). Several ENT academies have advocated to delay tracheostomies in COVID19 patients for 14 days or longer after intubation, some including PCR negativity, to reduce the risk of contagion [12-14]. An international consensus suggests that COVID19 tracheostomy should be performed after day 10 of invasive ventilation and considered only when patients display signs of clinical improvement [27]. In any case, all recommendations are currently based on patients not infected by the SARS-CoV-2. Also, the pressure of overcrowded ICUs with a high demand for equipment for mechanical ventilation had not been considered in any recommendation. This calls into question whether delaying a useful technique that potentially supports weaning and eventual decannulation has to be delayed because of a potential risk of contagion that has not been demonstrated so far. Due to the type of data collection, it could not be analyzed whether early or late tracheostomy made a difference in time of rate of weaning or decannulation. No comparison was made with long-term intubated, non-tracheostomized patients.
Technical issues in the execution for COVID-19 tracheostomy were highlighted after lessons learned in the 2003 SARS outbreak [28]: expert surgical teams, avoiding repeated connections and disconnections of ventilator circuits, minimal use of diathermy, stopping mechanical ventilation just before opening the trachea, closed suction circuits and negative-pressure room whenever feasible, as recommended in the consensus document elaborated later based on this experience [29]. But in COVID-19 pandemic, new scenarios have come up. In some centers, the onrush of cases in need of mechanical ventilation led to the creation of COVID-19 critical care units, sometimes located far from the operation theaters and most of our tracheostomies were performed at the bed-side. In the CovidTrach collaborative cohort [11], 55\% of tracheostomies were performed in the operation theatre and $45 \%$ in intensive care. In our cohort, the decision whether to perform a surgical or a percutaneous tracheostomy depended on the experience with the latter. More open tracheostomies (81.3\%) were performed by the group, as were in the CovidTrach collaborative cohort [11].

Complication rates in tracheostomy were low. With $2.6 \%$ hemorrhages requiring surgical revision was the most frequent one, similarly as in other reports [11,22] or the ARDS-related TRAC-MAN trial study [30]. Eventually, one patient died from bleeding. Among other adverse events, 5 $(0.2 \%)$ intraoperative deaths right after opening the trachea occurred.

Poor survival rates have been published for intubated critical patients without tracheostomy infected with SARSCoV-2 admitted to ICUs (Table 2), with mortality rates in large case reports of $26-54.4 \%$ [1, 2]. Case reports about tracheostomies in COVID-19 are scarce and with too few cases (Table 2) to allow further conclusion. The overall COVID-19-associated mortality in our cohort at the time of reporting was $23.7 \%(n=383 / 1616)$. In the CovidTrach collaborative cohort [11], only $12 \%$ mortality rate was found; however, $48 \%$ ( $n=221 / 465)$ of patients were still under mechanical ventilation at the time of completing the study. In our study, 391/1616 (24.2\%) were still under mechanical under ventilation at the cut-off time. A review of clinical
Table 2 Mortality rates of critical COVID-19 patients in ICUs without tracheostomy (Refs. [1-9])

\begin{tabular}{llll}
\hline Author & Time & No. patients ICU & Deaths \\
\hline ICNAR, Great Britain [1] & At May 22 & 5330 & $54.4 \%(n=2898)$ \\
Wu, China [2] & No data & 2.087 & $49 \%(\mathrm{n}=1023)$ \\
Grasseli, Italy [3] & Jan 1-28, 2020 & 1.591 & $26 \%(n=405)$ \\
Arent, USA [4] & Feb 1-March 5 & 15 & $67 \%$ \\
Wang, China [5] & Jan 1-25, 2020 & 13 & $15 \%(n=6)$ \\
Huang, China [6] & Dec 16-Jan 28, 2020 & 36 & $16 \%(n=6)$ \\
Yang, China [7] & No data & 37 & $81 \%(n=30)$ \\
Zhou, China [8] & Dec 29-Jan 31 & 32 & $96 \%$ \\
Yao, China [9] & 24 h post intubations & 202 & $10.40 \%$ \\
\hline
\end{tabular}


studies about tracheostomies in Acute Respiratory Distress Syndrome (ARDS) patients undergoing tracheotomy, with very damaged lungs, such as COVID-19 pneumoniae, shows a mortality rate of $23-30 \%[16,30]$.

In this pandemic scenario, with limited ICUs resources [10], our data show that about $52.1 \%(n=842 / 1.616)$ of patients undergoing tracheostomy get off the ventilator. The Covid Trach collaborative group from UK NHS reports similar weaning success rates $(52 \% ; n=219 / 465)$. The results of both reports suggest that the tracheostomy could be effective in the weaning and decannulation of COVID-19 patients, although data are preliminary yet and further studies are required.

\section{Conclusion}

COVID-19 recommendations on tracheostomy technique, perioperative management and self-protection have been very similar to SARS 2003 outbreak protocols. SARS-CoV-2 is a new virus that has led to a pandemic, with an onrush of COVID-19 cases that needed to be dealt with. In Spain, a large group of ENT colleagues from 120 hospitals created an innovative exchange of critical information through social media platform that proved usual for exchange of information and development of a common strategy. From 1,6161 patients, weaning could be achieved in 52\% with an overall mortality of $23.7 \%$. Nevertheless, $24.2 \%$ still remain connected to mechanical ventilation at the cut-off time despite the long-term follow-up due to chronicity and severity of COVID-19 disease. Tracheostomy may have helped to the recovery of more than 800 critically ill COVID-19 patients and subsequently released more than 800 mechanical ventilators for incoming patients, but it remains unclear whether tracheostomy influences the survival of these patients and which might be the ideal timing to perform it. Further studies are required to try to clarify these issues.

\section{Limitations}

This study has several limitations. Data were collected prospectively by an instant messaging group on-site. Subsequently, data are incomplete or missing in $14.5 \%$ of the cases. The follow-up time of 1 month seems to be too short as at the cut-off time. $24.2 \%$ patients were still tracheotomized and under mechanical ventilation.

Acknowledgements This article was made possible by the generous sharing of experience by Prof. Jesus M Culebras MD PhD, Professor of Surgery and member of the Royal Academy of Medicine and Surgery of Valladolid. He has given us advice on how to organize the data collection in our patients. He also reviewed the manuscript critically for important intellectual contents. We also acknowledge
Prof. MJ Gonzalez-Gimeno MD PhD, Associate Professor of ENT, for her expert advise on the topic. She has been involved in reviewing the manuscript version to be published and interpretation of results. A special acknowledge to Prof. Miguel Arístegui MD PhD, Head of ENT-Department of Gregorio Marañón Madrid Hospital for his expert comments in the manuscript. We also like to thank the Spanish Society of Otorhinolaryngology and Head and Neck Surgery (SEORL-HNS) and the clinicians and staff members of every hospital that took care of our patients with tracheostomy in the SARS-CoV-2 pandemic.

COVID ORL ESP Collaborative Group. Collaborators* (listed alphabetically): Albacete General Hospital, Aranzazu Perez-Fernandez, Sara Alcantara-Armenteros, Alicante General Hospital, Manuela Sancho-Mestre, Oscar Alemán-Lopez, Irene Monjas-Cánovas; Altahaia Xarxa Asistencial Manresa Hospital, M Dolors Deola-Trasserra, Vanessa Villarraga-Cova, Azor Carreras-Alcaraz, Esther MontaneSala; Alvarez Buylla Mieres Hospital, Esther Sota-Eguizabal; Araba Vitoria Hospital, Aihnoa Tolosa, Belen De la Iglesia, Rafael GarciaSardon; Aranda de Duero Burgos Hospital, Laura Diez; Barcelona Clinic Hospital, Eduardo Lehrer, Francisco Xavier Aviles-Jurado, Irene Sanchez; Basurto Bilbao Hospital, Kiara Tudela-Cabello; Bellvitge Barcelona Hospital Gabriel Huguet-Llull, Marta Mesalles-Ruíz, Ramon Jimenez-Montoya; Burgos HUBU Hospital, Ana NavazoEguïa, Blanca Galindo-Torres; Cabueñes Gijon Hospital, Marta Fernandez-Pello, Nuria Rodriguez-Prado; Caceres Hospital, Carmen Salazar, Francisco Ramos; Can Mises Ibiza Hospital, Juan Carlos Amor-Dorado; Castellon General Hospital, Marta Faubel-Serra, Rosana Almela-Cortes; Catalunya General Hospital, Valery NuñezCarrasco, Adriana Agüero-Medina, Juan Carlos-Villatoro, Roser Lopez-Diu, Selvyn Gonzalez-Melgan; CH Navarra Hospital, María Uzcanga-Lacabe, Marisela Cardier-Suárez; Ciudad Real General Hospital, Esther Úbeda-Fernández, Miguel Ángel Alañon-Fernández; Ciudad de Coria Hospital, Carlos Sanchez-Herrero; Cruces Barakaldo Hospital, Jose Antonio Municio-Martin, Luis Pascua-Gomez; Cruz Roja Madrid Hospital, Sergio Andrino-Martin, Alejandra Ayala; CUN Madrid Hospital, Bárbara Molina-Gil, Jorge De Abajo-Larriba; del Mar Barcelona Hospital, Zenaida Piñeiro-Aguín; Rio Hortega Valladolid Hospital, Elisa Gil-Carcedo, Javier Herrero-Agustín, Jorge FreijanesOtero, Mario Cuetos-Azcona; 12 de Octubre Madrid Hospital, Alfredo Garcia-Fernandez, Ignacio Jimenez-Huerta; CH Ferrol Hospital, Rosa Babarro-Fernández; Dr JMO Lanzarote Hospital, Felipe JunjgohannJofre, Antonio Martel-Lopez, Maria Dolores Martin-Sanchez; Dr Negrin Gran Canaria Hospital, Jesus Benitez-del Rosario, Alberto Sanchez-Tudela; El Bierzo Ponferrada Hospital, Diana Luorido, Monica Granda, Jose Miguel Tejeda; El Escorial Madrid Hospital, Antonio Martinez Ruiz-Coello; Elche Alicante Hospital, Antonio AlmodovarIniesta; Elda Alicante Hospital, Jesus Bonnin; Ferrol Hospital, Jacobo Chao-Vietes; Fuenlabrada Hospital, Estefanía Hernández-Garcia, Guillermo Plaza; Fundacion Jimenez Diaz, Jose Miguel VillacampaAuba, Alfonso Campos-Gonzalez, L Rubio Yanguas, Lucia BaguenaCampos, Alberto Encinas-Vicente, Raul Rubio-Yanguas; Gregorio Marañon Madrid Hospital, Alejandro Lowy-Benoliel, Daniel PolettiSerafini, Juan Antonio Pasamontes-Pingarron, Miguel Aristegui-Ruiz, Monica Hernando-Cuñado, Rosalia Souviron-Encabo, Tomas Martinez-Guirado, Mario Fernandez-Fernandez, Ricardo Gonzalez-Orus; Henares Coslada Hospital, Beatriz Molina-Montes, Raquel De la Fuente-Hernandez; Infanta Elena Huelva Hospital, Jesús CrovatoRojas; IFEMA Madrid; Infanta Elena Valdemoro Madrid Hospital, Cristian Ruminot, Daniella Laguado, Hander Acosta, María José Hernández-Garcia; Infanta Leonor Madrid Hospital, Alejandro ZuazaGonzalez, Carlos Domingo-Carrasco; Infanta Sofía Madrid Hospital, Cristina Valor-García, Javier Lopez-Martin; Infanta Cristina Badajoz Hospital, Tomas Mogollon-Cano; Joan XXIII Tarragona Hospital, Carla Meler-Claramonte, Juan Carlos Flores-Martín; La Candelaria Tenerife Hospital, Juanjo Arzok del Toro; La Fe Valencia Hospital, Alfonso Garcia-Piñero, Noelia Muñoz-Fernandez; La Paz Madrid Hospital, Antonio del Palacio, Blanca Mateos-Serrano, Isabel 
Garcia-Lopez, Laura Rodrigañez-Riesco, Paula Aragon, Teresa Rivera; La Princesa Madrid Hospital, Gustavo Eisenberg-Plaza, Inmaculada Fernandez-Robledo, Jorge Prada-Pendolero; Leon CAULE Hospital, Ignacio Alvarez-Alvarez, Maria Puente-Verez; Locus Agusti Lugo Hospital, Ana Quintana-Sanjuas, Pablo Parente-Arias; Mar Menor Murcia Hospital, Francisco García-Cordoba, Francisco Jose GarciaPurriños; Marques de Valdecilla Santander Hospital, Carmelo MoralesAngulo; Mateu Orfila Menorca: Simara Rodriguez-Rondon, Diana Lopez-Lopez; Miguel Servet Zaragoza Hospital, Rafael FernandezLiesa; Militar Zaragoza Hospital, Amaya Lázaro-Sánchez, I AlonsoAlonso; Moises Brogui Barcelona Hospital, Michalina Rusiecka, Rosa Delia Ramirez, Javier Vila; Mollet Barcelona Hospital Angela Bellmunt-Fontanet, Victoria Montoro-Martinez; Morales Masegur Murcia Hospital, Francisco Piqueras, Vania Novoa-Morales; Mutua Terressa Hospital, Gabriela Simonetti, Laura Palomino; Niño Jesus Madrid Hospital, Enrique Guillen-Lozada, Raimon Gracia; Ntra Stra Sonsoles Avila Hospital, Maria Jesus Velasco; Palencia Hospital, Ignacio Alonso-Castiñeira, Maria Hernandez; Parc Tauli Sabadell Hospital, Carlota Rovira-Ramos, Juan Jose Diaz-Argüello, Yolanda EscamillaCarpintero; Perpetuo Socorro Badajoz Hospital, Pablo Torrico-Roman; Plato Barcelona Hospital, Carlos Calvo-Navarro, Ignacio Viza-Puiggros; Principe Asturias Alcala Madrid Hospital, Cristina Vaduva, Juan Higuera-Lucas, Jose Ignacio Tato, Teresa Rivera-Rodriguez; Puerta de Europa Algeciras Hospital, Diego Rodriguez-Contreras, Antonio Caravaca-Garcia; Punta del Sur Madrid, Alfredo Garcia; Quiron Ciudad Real Hospital, José Manuel Morales-Puebla; Quiron Madrid La Luz Hospital Carlos Ruiz-Escudero; Quiron Sagrado Corazon Sevilla Hospital, E Lozano-Reina, Juan Manuel Maza-Solano; Quiron Salud Zaragoza Hospital, Jorge Alfaro-Garcia; Ramon y Cajal Madrid Hospital, Fatima Sanchez-Fernandez, Lourdes Montes-Jovellar, Mar Medina, Rafael Barbera; Reina Sofia Murcia Hospital, Alfonso MarcoGarrido, Isabel Cremades-Navalon; Requena Hospital, Javier GarcíaCallejo; Rey Juan Carlos Hospital, C Garcia Bastida, Raimundo Gutierrez-Fonseca; Ruber juan Bravo Madrid Hospital Jorge Prada-Pendolero; Salamanca Clinic Hospital, Angel Muñoz-Herrera, Marta Calvo; San Agustin Aviles Hospital, Carmen Rosal-Fraga; San Carlos Madrid Clinic Hospital, Mari Cruz Iglesias-Moreno, Jesus Gimeno-Hernández; San Juan de Dios Barcelona Hospital, Cristina A Vázquez-Romero; San Pau i Sta Tecla Tarragona Hospital, Fabian Alzate-Amaya; Sanitas La Zarzuela Madrid Hospital, Estefanía Hernández-Garcia, Laura Palomino, Marta Alcaraz; Sant Joan de Reus Hospital, Coia Romeu-Figuerola, Maria Foglia-Fernandez; Santiago de Compostela Hospital, Cristina Dios-Loureiro, Isabel GonzalezGuijarro; SCIAS Barcelona Hospital, Rafael Vera-Llao; Segovia Hospital, Rosa Sancho-Calvo; Severo Ochoa Leganes Madrid Hospital, Jesus Jose Ramos-Fernandez, Jose Carlos Casqueiro, Mar LassodelaVega, Paula Martinez-Pascual, Silvia Dominguez-Ovejas; SJD San Boi Hospital Rafael Vera-Llao; Son Espases Mallorca Hospital, Eduardo Morera-Serna, Jacoba Alba-Mesquida; Son Llatzer Mallorca Hospital, Alfonso Bonilla-Perez; Sta Barbara Soria Hospital Javier Martinez-Subias; Sureste Arganda del Rey Madrid Hospital, Jesus M Martinez-Salazar; Talavera Hospital, Antonio Martinez-Lapeña; Toledo Virgen de la Salud Hospital, Rocio Corrales-Millan, Rosario Ruiz-Gomez; Torrejon Madrid Hospital, Nieves Mata; Urduliz Hospital, Laura Gerarda Cianci-Jaimes, Valencia General Hospital, Enrique Zapater-Latorre, Jose Ramon Alba-Garcia, Miriam Natsuki OishiKonari, Beatriz Pallares-Marti, Andrea Rubio-Fernandez; Valladolid Clinic Hospital, Jaime Santos-Pérez; Vic Hospital, Albert IdigoraPlanas; Villaba General Hospital, Alvaro Sanchez-Barrueco, Ignacio Alcala-Rueda; Virgen Arreixaca Murcia Hospital, Ruben Jara-Rubio; Virgen del Rocio Sevilla Hospital, Estefanía Lozano, Isabel TiradoZamora; Virgen Macarena Sevilla Hospital, Zamora Virgen de la Concha Hospital, Enrique Coscaron-Blanco, Soledad Suarez-Ortega; Zaragoza Clinic Hospital, Guillermo Gil-Grasa, Maria Jose LavillaMartin de Valmaseda, Jose Miguel Sebastian; University Hospitals of Derby and Burton Nottigham (GB)* invited hospital, Hazem Nijim;
Jesus Dominguez-Calvo; Universidad Europea, Maria Jose GonzalezGimeno; University of Leon, Ana Carvajal-Urueña, Luis Anel, Manuel Gonzalo-Orden.

Author contributions CMV, CPMR and MBB develop the concept and designed the study. CMV had the responsibility of the data collection and data analysis. CMV wrote the manuscript. MBS made final corrections. All authors have revised the manuscript and gave approval for the published version.

\section{Compliance with ethical standards}

Conflict of interest We have no conflicts of interest to disclose.

\section{References}

1. ICNAR, Great Britain Intensive Care National Audit and Research Centre (2020) ICNARC report on COVID-19 in critical care. https ://www.icnarc.org/Our-Audit/Audits/Cmp/Reports. Accessed 22 May 2020

2. Wu Z, McGoogan JM (2020) Characteristics of and important lessons from the coronavirus disease 2019 (COVID-19) outbreak in China: summary of a report of 72314 cases from the Chinese Center for Disease Control and Prevention [published online ahead of print, 2020 Feb 24]. JAMA. https://doi.org/10.1001/ jama. 2020.2648

3. Grasselli G, Zangrillo A, Zanella A et al (2020) Baseline characteristics and outcomes of 1591 patients infected with SARSCoV-2 admitted to ICUs of the Lombardy Region, Italy [published online ahead of print, 2020 Apr 6]. JAMA 323(16):1574-1581. https://doi.org/10.1001/jama.2020.5394

4. Arentz M, Yim E, Klaff L et al (2020) Characteristics and outcomes of 21 critically ill patients with COVID-19 in Washington State [published online ahead of print, 2020 Mar 19]. JAMA 323(16):1612-1614. https://doi.org/10.1001/jama.2020.4326

5. Wang D, Hu B, Hu C et al (2020) Clinical characteristics of 138 hospitalized patients with 2019 novel coronavirus-infected pneumonia in Wuhan, China [published online ahead of print, 2020 Feb 7]. JAMA 323(11):1061-1069. https://doi.org/10.1001/ jama.2020.1585

6. Huang C, Wang Y, Li X et al (2020) Clinical features of patients infected with 2019 novel coronavirus in Wuhan, China [published correction appears in Lancet. 2020 Jan 30]. Lancet 395(10223):497-506. https://doi.org/10.1016/s0140 -6736(20)30183-5

7. Yang X, Yu Y, Xu J et al (2020) Clinical course and outcomes of critically ill patients with SARS-CoV-2 pneumonia in Wuhan, China: a single-centered, retrospective, observational study [published correction appears in Lancet Respir Med. 2020 Apr;8(4):e26]. Respir Med 8(5):475-481

8. Zhou F, Yu T, Du R et al (2020) Clinical course and risk factors for mortality of adult inpatients with COVID-19 in Wuhan, China: a retrospective cohort study [published correction appears in Lancet. 2020 Mar 28;395(10229):1038] [published correction appears in Lancet. 2020 Mar 28;395(10229):1038]. Lancet 395(10229):1054-1062. https://doi.org/10.1016/s0140 $-6736(20) 30566-3$

9. Yao W, Wang T, Jiang B et al (2020) Emergency tracheal intubation in 202 patients with COVID-19 in Wuhan, China: lessons learnt and international expert recommendations [published online ahead of print, 2020 Apr 10]. Br J Anaesth. https://doi. org/10.1016/j.bja.2020.03.026 
10. Matheny Antommaria AH, Gibb TS, McGuire AL et al (2020) Ventilator triage policies during the COVID-19 pandemic at U.S. Hospitals associated with members of the association of bioethics program directors [published online ahead of print, 2020 Apr 24]. Ann Intern Med. https://doi.org/10.7326/m20-1738

11. COVIDTrach, Nick JI Hamilton (2020) COVIDTrach; the outcomes of mechanically ventilated COVID-19 patients undergoing tracheostomy in the UK: Interim Report 22nd May 2020 medRxiv 2020.05.22.20104679. https://doi.org/10.1101/2020.05.22.20104 679

12. Parker N, Schiff B, Fritz M, Rapaport S, Schild S, Altman K et al (2020) Tracheotomy recommendations during the COVID-19 pandemic. American Academy of Otorhinolaryngology-Head \& Neck Surgery.https://www.entnet.org/content/tracheotomy-recom mendations-during-covid-19-pandemic

13. Engels PT, Weitzel E, Witterick IJ, Khalili S, Corsten M, Tewfik MA et al (2020) Recommendations from the CSO-HNS taskforce on performance of tracheotomy during the COVID-19 pandemic. Canadian Society of Otolaryngology-Head and Neck Surgery. https://www.entcanada.org/wpcontent/uploads/COVID-19-Guide lines-CSOHNS-Task-Force-Mar-23-2020.pdf. Accessed 6 Apr 2020

14. ENT-UK Guideline (2020). https://www.entuk.org/tracheostomyguidance-duringcovid-19-pandemic

15. Health Ministry of Spain (2020) Informe sobre la situación de COVID-19 en España ${ }^{\circ} 31.14$ de mayo de

16. Abe T, Madotto F, Pham T et al (2018) Epidemiology and patterns of tracheostomy practice in patients with acute respiratory distress syndrome in ICUs across 50 countries. Crit Care 22(1):195. https ://doi.org/10.1186/s13054-018-2126-6

17. Stubington TJ, Mallick AS, Garas G, Stubington E, Reddy C, Mansuri MS (2020) Tracheotomy in COVID-19 patients: optimizing patient selection and identifying prognostic indicators. Head Neck. https://doi.org/10.1002/hed.26280

18. Riestra-Ayora J, Yanes-Diaz J, Penuelas O, Molina-Quiros C, Sanz-Fernández R, Martin-Sanz E (2020) Safety and prognosis in percutaneous vs surgical tracheostomy in 27 patients with COVID-19. Otolaryngol Head Neck Surg. https://doi. org/10.1177/0194599820931801

19. Piccin O, Albertini R, Caliceti U et al (2020) Early experience in tracheostomy and tracheostomy tube management in Covid-19 patients [published online ahead of print, 2020 May 7]. Am J Otolaryngol. https://doi.org/10.1016/j.amjoto.2020.102535

20. Takhar A, Walker A, Tricklebank S et al (2020) Recommendation of a practical guideline for safe tracheostomy during the COVID19 pandemic [published online ahead of print, 2020 Apr 21]. Eur Arch Otorhinolaryngol. https://doi.org/10.1007/s00405-02005993-x

21. D'Ascanio L, Latini G, Pandolfini M, Giardini D (2020) Letter to the editor regarding "corona-steps for tracheotomy in COVID-19 patients: a staff-safe method for airway management". Oral Oncol. https://doi.org/10.1016/j.oraloncology.2020.104731

22. Mattioli F, Fermi M, Ghirelli M et al (2020) Tracheostomy in the COVID-19 pandemic. Eur Arch Otorhinolaryngol. https://doi. org/10.1007/s00405-020-05982-0

23. Deng ZF, Zhu T, Ding YJ et al (2020) Zhonghua Er Bi Yan Hou Tou Jing Wai Ke Za Zhi 55:E009. https://doi.org/10.3760/cma.j. issn.1673-0860.2020.0009

24. Hiramatsu M, Nishio N, Ozaki M et al. Anesthetic and surgical management of tracheostomy in a patient with COVID-19. Auris Nasus Larynx. https://doi.org/10.1016/j.anl.2020.04.002

25. Andriolo BN, Andriolo RB, Saconato H, Atallah ÁN, Valente O (2015) Early versus late tracheostomy for critically ill patients. Cochrane Database Syst Rev 1(1):CD007271. https://doi. org/10.1002/14651858.cd007271.pub3

26. Adly A, Youssef TA, El-Begermy MM, Younis HM (2018) Timing of tracheostomy in patients with prolonged endotracheal intubation: a systematic review. Eur Arch Otorhinolaryngol 275(3):679-690. https://doi.org/10.1007/s00405-017-4838-7

27. McGrathn BA, Brenner MJ, Warrillow SJ et al (2020) Tracheostomy in the COVID-19 era: global and multidisciplinary guidance. Lancet Resp Med. https://doi.org/10.1016/S2213-2600(20)30230 $-7$

28. Tay JK, Khoo ML, Loh WS (2020) Surgical considerations for tracheostomy during the COVID-19 pandemic: lessons learned from the severe acute respiratory syndrome outbreak [published online ahead of print, 2020 Mar 31]. JAMA Otorhinolaryngol Head Neck Surg. https://doi.org/10.1001/jamaoto.2020.0764

29. Bernal-Sprekelsen M, Avilés-Jurado FX, Escudero JÁ et al (2020) Consensus document of the Spanish Society of Intensive and Critical Care Medicine and Coronary Units (SEMICYUC), the Spanish Society of Otorhinolaryngology and Head and Neck Surgery (SEORL-CCC) and the Spanish Society of Anesthesiology and Resuscitation (SEDAR) on tracheotomy in patients with COVID-19 infection] [published online ahead of print, 2020 May 11]. Acta Otorhinolaryngol Esp. https://doi.org/10.1016/j.otorr i.2020.04.002

30. Young D, Harrison DA, Cuthbertson BH, Rowan K, TracMan Collaborators (2013) Effect of early vs late tracheostomy placement on survival in patients receiving mechanical ventilation: the TracMan randomized trial. JAMA 309(20):2121-2129. https:// doi.org/10.1001/jama.2013.5154

Publisher's Note Springer Nature remains neutral with regard to jurisdictional claims in published maps and institutional affiliations. 